\title{
Pierre Bourdieu as Cognitive Sociologist ${ }^{1}$
}

\section{Omar Lizardo}

olizardo@nd.edu

${ }^{1}$ Chapter to appear in The Oxford Handbook of Cognitive Sociology edited by Wayne H. Brekhus and Gabriel Ignatow.

${ }^{2}$ University of Notre Dame, Notre Dame, IN, 46556. Tel: (574) 631-1855. 


\begin{abstract}
It is now well established that Pierre Bourdieu's work can be interpreted as a form of cognitive sociology. Yet, given that the term "cognitive" has a variety of meanings, the question of where Bourdieu's project of cognitive sociology fits into other cognitively grounded approaches in the social sciences remains open. In this chapter, I argue that if Bourdieu is to be considered a cognitive theorist, then there is only one way in which we can interpret his conception of cognition, and that is as a form of embodied cognition. I distinguish different senses of the term embodiment and specify how they show up in Bourdieu's work. I discuss two broad sets of empirical phenomena---the "hard" and "soft" embodiment of culture---that have recently been identified and argue that their discovery represents a vindication of the prescience and promise of Bourdieu's version of cognitive sociology. I close by providing indications how we can further an empirically grounded version of Bourdieu's cognitive sociology today.
\end{abstract}

Keywords: Bourdieu, Embodiment, Cognition, Culture, Language, Ideology. 


\section{Introduction}

It is now well established that Pierre Bourdieu's overall oemvre can be interpreted, in its essence, as a form of cognitive sociology (Lizardo 2004). Yet, given the broad scope of what the notion of cognition is taken to refer to across the human and social sciences (Wilson 2004; Zerubavel, this volume), the question of what kind of cognitive sociology Bourdieu was proposing can become a subject for debate (Lizardo 2011, 2012). In this chapter, I argue that if Bourdieu is to be thought of as a theorist of the relationship between the "social" and the "cognitive"---as he characterized it himself (Bourdieu 1996b:1-3)---then there is only one way in which we can interpret his conception of the latter notion, and that is as a form of embodied cognition (Clark 1997; Lizardo and Strand 2010; see also Cerulo, this volume; Ignatow, this volume; Martin, this volume).

To put succinctly, embodied cognition approaches are distinct in viewing bodily structure and the particular experiences it affords as an essential aspect (both in terms of structure and process) of the activities that have usually been labeled "cognitive." These include perception, categorization, morality, social interaction, and reasoning among others (Lakoff and Johnson 1999). The thesis of embodied cognition stands opposed to "classical" approaches in cognitive science and artificial intelligence developed in the 1950s and 1960s that viewed cognition as essentially a form of "computation" conceptualized as the manipulation and "processing" of abstract symbols with no natural connection to the body and the world (Dreyfus 1992; Lakoff and Johnson 1999). Within this latter paradigm, the mind was only contingently embodied in the brain, and its operations could be described as a "physical symbol system" of which (universal) computers were also an instance (Newell 1980). Embodied or "enactive" cognitive neuroscience is now considered the 
most promising strand of work in the field (Chemero 2011; Hutto and Myin 2013; Wheeler 2005). It is also the one that displays the most potential of unifying the cognitive neurosciences with all the other human and social sciences (Wilson 2004). In these respects, Bourdieu's approach can be considered as not only eminently on the right track and ahead of his time, but also a still relatively underexplored source of fundamental insights into the relation of culture, action, and cognition (Lizardo 2004).

The notion of embodiment or embodied cognition is itself polysemous, carrying distinct meanings across different areas of inquiry (Rohrer 2010; Wilson 2002). Thus, even if we are to agree that Bourdieu's cognitive sociology belongs within embodied cognitive science, we still need to make clear what we mean by embodiment. In what follows, I differentiate some related (but analytically distinct) meanings of embodiment as these may help us specify exactly how Bourdieu is a cognitive sociologist. I then consider two recently established empirical phenomena relevant to the embodiment discussion as it relates to Bourdieu: What has been referred as "the hard" and "soft embodiment of culture." As we will see, the specification of these phenomena in cognitive and social psychology represents an impressive empirical vindication of the basic principles of embodied cognitive sociology developed by Bourdieu. I close by outlining the conceptual and empirical challenges, focusing on contemporary cultural theory in sociology, that come from considering the possibility that what has traditionally been referred to as "culture" may come to be "internalized" by actors in particularly "hard" and "soft" ways.

\section{Embodiment in Contemporary Social Analysis}

Theoretical reflections on "embodiment" are now ubiquitous in the human, social, and cognitive sciences (Lizardo 2015). In the social sciences, a concern with embodiment has influenced areas as disparate as studies of science and technology, 
cultural and cognitive sociology, organizational analysis, interactionist theory, ethnography, the sociology of emotions, the sociology of gender, and the sociology of religion. The basic impulse that holds together these disparate appeals to the notion of embodiment is a rejection of classical, and postclassical (symbolist and structuralist) models of enculturation and action. In this respect, the developmental arc of Bourdieu's basic notions (e.g. habitus, practice, field) can be read as a protracted movement away from disembodied structuralist accounts of cultural meaning as an abstract relation between absent differences, and towards an embodied and embedded view of cognition and perception as grounded in bodily action (Lizardo 2011).

Senses of Embodiment

(a) The embodiment of cultural meaning.- Sometimes embodiment theorists have in mind a particular approach to the analysis of (linguistic) meaning. For instance, in Lakoff and Johnson's (1980) influential conceptual metaphor theory, the notion of embodiment is brought in to explain the asymmetric dependence of certain conceptualizations of abstract domains on core domains of experience. For instance, MORE IS UP ("inflation rates have shot to the sky") conceptualizes abstract quantity in terms of vertical movement in space; the STATES ARE LOCATIONS metaphor ("our relationship is stuck in a quagmire") conceptualizes the (lack of) progression in a relationship as being unable to move from a fixed location. Because the domain of verticality or locomotion in space are fundamental to our experience as embodied beings, metaphors drawn from these source domains are systematically recruited to conceptualize more abstract realms of experience but not the other way around (Lakoff and Johnson 1999). Recent attempts to move beyond "amodal" theories of meaning (the notion that knowledge is stored in long-term memory in a format separate from the sensory modalities) can also be thought as relying on the notion of 
the embodiment of conceptual meaning (Barsalou 1999; Ignatow 2007). This naturally extends to a consideration of the embodiment of lexical, grammatical, and linguistic meaning as is characteristic of modern Cognitive Linguistics (Rohrer 2010).

This notion of embodiment undoubtedly played a central role in Bourdieu's cognitive sociology. For instance, Bourdieu's discussion of the "practical metaphors" governing the spatial and visual texture of the Kabyle household (first published in French as Bourdieu 1970), is essentially an anticipation of the Lakoff-Johnson conception of embodiment as a way to move beyond the "digital" (disembodied) conception of meaning developed in Levi-Straussian structuralism (Bourdieu 1996a:314-315). In Bourdieu's account, the Kabyle household is organized around a set of bodily grounded oppositions activated during routine actions, such as left-right, front-back and so on (Bloch 1986), some of which are inscribed to the very (e.g. East/West) orientation of the various regions of the house in relation to the activities that go on outside. These, come to be experientially correlated with certain qualities (dark/light, inside/outside, dry/moist) of the setting in which actions (e.g. sleeping, cooking, entertaining guests) occur and the calendrical rhythms associated with them. These are inclusive of the typical presence of members of each gender in each region, which come to attach "gendered" meanings to these qualities, actions, and spaces, thus resulting in more "abstract" correspondences identified in classic structuralism (e.g. male : dry :: female : wet).

(b) The embodiment of subjectivity.- Here the notion of embodiment is a platform with which to move beyond certain long-standing aporias in the analysis of mind, reason, and subjectivity that come from the Western rationalist (Platonic and Descartian) and critical-rationalist (Kantian/Hegelian) traditions. The basic idea here (particularly powerful in contemporary feminist philosophy (e.g. Grosz 1987)) is that the notion of a disembodied subject independent of bodily sensations, experience, perspective, and emotion is a fiction. Embodiment provides an escape from the 
"view from nowhere" conception of subjectivity, providing instead a platform from which to theorize the subject as an inherently perspectival phenomenon.

Following the lead of such thinkers as Heidegger and Merleau-Ponty, persons are conceived as embodied subjects endowed with the rootedness, particularity, and finitude that such a condition entails (Dreyfus 1991). Philosophical accounts of embodiment are sometimes brought into dialogue with classical sources in social theory (e.g. Marx, Weber, Durkheim) in order to either point to the drawbacks that come from the inheritance of pernicious philosophical postulates by the Classical theorists, or to point to their prescient attempts to escapes from those postulates. In this respect, Bourdieu's somewhat under-appreciated (perhaps due to the its particular relevance to the French context) critique of the Sartrean notion of the self (or "I") as a "pure" a-substantial center of consciousness that is only contingently embodied is strongly rooted on this "philosophical" account of cognition as inherently embodied inspired by Merleau-Ponty (Crossley 2001).

(c) The embodiment of socio-cultural activity.- Alternatively, analysts may use the notion of embodiment as a sensitizing concept that is brought to the field to enrich situated descriptions of concrete empirical settings. This may happen in various forms, from recent symbolic interactionist attempts to link long-standing concerns with the development of meaning via significant symbols with the concrete challenges and opportunities that come from considering the role of the lived body in this process (Waskul and Vannini 2006), to more recent attempts (exemplified in Loic Wacquant's (2004b) call to "follow Bourdieu to the field") to enrich analytical ethnography with first-person accounts of the acquisition of practical dispositions (both "cognitive" and "motor"). Both traditions (among others) concentrate on using a perspective of embodiment to provide richer accounts of lived experience in the field (which may involve dramatic cognitive, emotive, and physical transformations). Wacquant's "carnal sociology" (2004a), therefore, can be considered an extension and 
radicalization of the embodied cognition account of mind and activity first developed in Bourdieu's fieldwork among the Kabyle and later extended to the understanding of taste and cognition in the France of his time (Bourdieu 1984, 1996b), Ignatow, this volume).

d) The external embodiment of cognition.- This perspective is more common in social scientific studies of science and technology including the study of interactions between persons, artifacts, and lived environments. Besides being "embodied" in the (lived) physical body of persons, knowledge and experience also comes to be embodied in a variety of extra-personal sites. Here a concern with embodiment links to a sensitivity to materiality as an important dimension of socio-cultural life (McDonnell 2016). Here embodiment is a catch all phrase to denote most forms of the cognitive externalization of meaning and action, and the problem of interfacing physical bodies with externalized aids to knowledge, perception, and experience (prototypically scientific instruments). This sense of embodiment is muted (but not absent) in Bourdieu's work, probably due to the residual concern with the structural analysis of discursive and symbolic systems that characterized the majority of his empirical work (Lizardo 2011).

e) The Embodiment of the Cognitive Unconscious.- This sense of embodiment, more common in the cognitive than in the social sciences (see for instance, Lakoff and Johnson's (1999) work on embodiment in philosophical discourse) gains more relevance in social and cultural analysis via the influence of practice theory. This is the strongest sense in which Bourdieu's work can be considered a form of cognitive sociology, since for Bourdieu, the cognitive unconscious was the actual repository of collective representations in the Durkheimian sense (Lizardo 2004).

Here, the body (and embodiment) is the site of the "internalization of exteriority" so that environmental conditionings are transformed into active dispositions pre-adapted to the world and operating in an implicit state (Strand and 
Lizardo 2015). Embodiment plays a key role here because what is from another perspective seen as rooted in representational abstractions (e.g. values, beliefs) are conceived here as rooted in fundamental comportments of the body (Lizardo 2009). Enculturation, then resolves itself in the conditioning of the body to generate the dispositional potentialities required in each situation (Lizardo 2017; Strauss and Quinn 1997). This sense of embodiment provides a rare avenue of dialogue between cultural analysts in anthropology and sociology, and cognitive scientific work concerned with theorizing implicit and unconscious phenomena (Cerulo 2015; Wacquant 2013). This may range from cognitive-emotive appreciative, moral, and cognitive dispositions, or "procedural" competences embodied as know-how, and skill (Downey 2014; Pálsson 1994)

\section{Making Sense of Embodiment}

This brief (and by design selective) consideration of the various usages of the notion of embodiment in the contemporary social and cultural sciences provides us with a platform to differentiate between different analytical deployments of the notion as it pertains to our consideration of Bourdieu's cognitive sociology. I will take as my key consideration the question of what consequences (if any) do these different conceptions of embodiment have for how we understand the process via which persons become "encultured" with the caveat that Bourdieu's own version of cognitive sociology did not itself conceive of the internalization of experience as "enculturation" (Lizardo 2011). The reason for this choice is that while "culture" as an analytic category may not have been useful to Bourdieu, it is non-negotiable in the contemporary landscape of the social and human sciences (Lizardo 2017). The question to ask therefore, is the extent to which the basic premises of Bourdieu's own cognitive sociology, built as they are on a particularly committment to some of the notions of embodiment discussed earlier, pose "trouble" for traditional conceptions 
of culture and enculturation dominant in the social sciences today.

Business as usual in contemporary cultural analysis faces a bigger challenge depending on which (combination) of the senses of embodiment we adopt. The difference in emphasis across these conceptions are important because they in part determine both the phenomena that are conceived as being operative in a given empirical setting and thus the empirical material we as analysts (and our methods) will be sensitive to. For instance, a theorist who does not see linguistic meaning as embodied in sense (a) above will miss the plethora of conceptual metaphors whose source domain is embodied even when her subjects express them overtly (Ignatow 2007, 2009a, 2016). In the same way, an analyst blind to the embodiment of culture in the cognitive unconscious will perforce overestimate the influence of explicit (e.g. linguistic) factors (Lizardo 2017). In this respect, the more we move away from embodiment as an acknowledgment of the broad experiential limits and potentialities opened by our status as embodied subjects (sense $b$, $c$, and $d$ ), and more towards embodiment as the bodily substate of meaning and experience (senses $a$, and $e$ ) the more problematic is a consideration of meaning as rooted in bodily experience and the body as the repository of the cognitive unconscious from standard accounts of the link between culture and action in social theory.

Externalized embodiment accounts (as in the classic work of anthropologist Edwin Hutchins (1995)) have also brought the field forward, but are less directly related to the central problem of internalization and enculturation in cultural analysis. Because they rely on externalized, materially manifested meaning, externalization theorists do not have to worry about the hard problem of enculturation and internalization (Collins 2010). In many respects, the traditional observational tools of the social sciences (ethnography and the in depth interview) have always been more calibrated to capture processes of meaning externalization than they have the more covert process of "internalization" and enculturation. 
While "philosophical" conceptions of embodiment have had a salutary role in reorienting cultural analysis, they have not changed the basic parameters of contemporary research in the social and cultural sciences a fundamental way. The problem is that in taking "embodiment" as a constitutive category rather than as an empirically specifiable phenomenon, philosophically oriented embodiment theories err on the side of over-generalization and over-inclusiveness. This may account for the lack of bite of Bourdieu's critique of Sartre as a point of departure for discussions of embodiment in contemporary social and cultural theory.

Both embodiment of meaning and phenomenological accounts have fared better precisely because they stick closer to the their respective empirical settings (Uhlmann 2000). Lakoff and Johnson's work on conceptual metaphor has launched a veritable revolution in the contemporary study of language and meaning; the embodied-phenomenology turn in ethnography has revitalized qualitative fieldwork across a variety of areas, moving the analyst from mere participant observation to "observant participation" (see for instance, the work of Desmond (2007), Wacquant (2004a), Mears (2011), Winchester (2008), and Pagis (2010)---among others---in the United States).

\section{Bourdieu and The Hard Embodiment of Culture}

There is now a systematic body of evidence across the social and cognitive

sciences showing that (a) persons come to embody (via direct experience) forms of "personal culture" (Lizardo 2017; Strauss and Quinn 1997), (b) that this stock of personal culture can be systematically activated, retrieved and used in context (Higgins and Brendl 1995), (c) that once activated personal culture can have a powerful influence on subsequent cognition, emotion, judgment, and action across settings (Barsalou et al. 2003), and (d) the activation of this culture happens not via linguistic or symbolic elicitation or interpretation mechanisms but via direct 
manipulation (e.g. changes in posture) of states of the body. I refer (following the psychologists Dov Cohen and Angela Yeung (2009)) to this culture as having been subjected to "hard embodiment." As Cohen and Yeung make clear the hard embodiment phenomenon was directly presaged and first articulated in Bourdieu's discussion of internalization in Logic of Practice.

In Cognitive Psychology, the phenomenon of hard embodiment of culture was first hinted at in (now well-established) research establishing the sensitivity of the personal use of high-level cognitive and affective processes to seemingly "irrelevant" states of the body. The deployment of seemingly "abstract" concepts and ideas seems to have a strong dependence on the "state of the body" of the person at the time in which those concepts are being put to use. These bodily states carry a form of "analog" meaning that may elicit semantically compatible (or interfere with semantically incompatible) cognitions and emotions (Glenberg and Gallese 2012).

Thus, persons forced to nod while attempting to process a persuasive message under time pressure are more likely to agree with the speaker; persons made to carry a heavy object when listening to a message give higher estimates of its importance (e.g. "weight"); persons forced to hold a pen between their teeth (eliciting a forced smile) report a more positive mood afterward; persons who are forced to puff their chest and open their arms are more likely to report feelings of exaltation and pride; when asked to recognize "powerful" words under time pressure, persons find it easier to do it when the words are presented in the upper part of the computer screen than when they are forced to look at the lower part, and so on (see Gallagher 2005 for a review).

Essentially the notion of hard embodiment extends this embodied elicitation mechanism towards more complex elements usually studied under symbolic and representationalist approaches to culture: namely, belief and value systems (Lizardo 2009). The basic idea, is that rather than being first acquired via the direct internalization of elaborate symbolic representations, belief and value systems are first 
inculcated via the routine enactments of bodily comportments and only later elaborated in terms of high level symbolic representations. This is precisely the mechanism that Bourdieu (1990) proposed when interpreting his ethnographic data from the Kabyle in Logic of Practice (and as first codified in Mauss' classic essay on "techniques of the body" (1973 see also Ignatow, this volume)). Routine enactments include specific ways of "sitting, standing, walking, eating, praying, gazing, hugging, relaxing, washing, and so on” (Cohen and Leung 2009:1279; see also Leung et al. 2011). In this way, the "strong" senses of embodiment discussed above can readily understand how cognition can be embodied within a socio-cultural context (Schubert and Semin 2009).

The discovery of hard embodiment of culture shows that the body functions precisely as described in Bourdieu's cognitive sociology: As a "living memory pad" (Bourdieu [1990: 68]); the substrate of the cognitive unconscious where culture is embodied in a particularly durable way (in the sense (e) above). There is a systematic non-arbitrary link between the meaning (encoded in "analog" or "iconic" form) in the bodily posture and the abstract high-level meaning (or emotional quality) elicited by that posture. A classic example of this connection is the link between power and the above/below axis in "vertical classification" discussed in early work by Schwartz (1981) in sociology and corroborated experimentally in a series of studies by Schubert (2005) in psychology. The elicitation of hard-embodied culture may be expanded and made even more complex by embedding routine enactments in externalized forms of embodiment (sense (d) above), thus recruiting artifacts (with their specific affordances) and constructing (and changing) specific material environments that predispose persons towards particular cognitive and emotional states consistent with abstract belief and value systems. For instance, Bourdieu's (1991:75) classic discussion of the situated use of the skeptron to both display (to others) and elicit (in self) feelings of the authority of the spoken word is an example of this latter version of the effect. 
In this way, the notion of hard-embodiment links most directly to senses (a) and (e) above related to the embodiment of cultural meaning. Postures (standing tall versus slouching), ways of doing things (energetically or lethargically, with sweeping or fine-grained movements) and position in physical space (standing above or below; sitting at the "head" of the table) carry experiential, primary, embodied meaning (Schubert 2005; Toren 1999). For instance, partaking of the same substance (via ingestion), non-negotiable leads to the conception we share a common substance. In this respect, most instances of constituting "communal" relations are "hard embodied" in rituals sharing this aspect (Fiske 2004). These "hard embodied" meanings then feed into those encoded in more complex ideological systems that require explicit symbolic representation. The direction of meaning construction is asymmetric, in the sense that relatively disembodied realms of meaning (e.g. abstract philosophical principles) must recruit this hard-embodied culture for semantic specification (via conceptual metaphors and analogies) and not the other way around (Lakoff and Johnson 1999).

The key lesson is that when the things that social scientists refer to as "culture" are learned via hard embodiment, complex orientations can be elicited via the habitual incitement to adopt specific bodily postures during the performance of typical everyday routines by socialization agents. In this way, routine enactments prepare the ground for the activation, retrieval, and access of more complex cognitive emotive complexes, including beliefs, ideologies, worldviews, and cosmologies. These may include gender-based ideologies (Uhlmann and Uhlmann 2005), or more complex "value" complexes (Hitlin and Piliavin 2004). In this respect the proposition that "complex sentiments may be embodied, in the sense that the physical movements of our body promote or predispose us to adhere to certain mindsets, and these mindsets can be associated with relatively complex and nuanced judgments about the world and moral behavior" (ibid) has gone from theoretical speculation to 
well-supported thesis.

For instance, Cohen and Leung show that a classic cultural pattern in the functionalist tradition, namely the universalism-particularism distinction, can be hard-embodied in the above-sense. In a study designed to tap how the availability of these different cultural schemas depended on certain patterns of embodiment researchers asked both Anglo-American and Asian-American participants to respond to a series of ethical dilemmas that involved accessing either universalistic and particularistic cultural patterns. Researchers found that when participants were asked to embody a physical posture of rectitude (holding your chin above a string placed at the required height) while answering the questionnaire both Anglo and Asian American participants were more likely to provide answers consistent with universalism. However, when asked to provide answers embodying a more "relational" posture (e.g. hugging a pillow) Asian-Americans but not Anglo-Americans were more likely to provide answers consistent with particularism (Cohen and Leung 2009: 1283).

The group-specificity of this result suggests, as argued above, that embodiment can only evoke pre-existing moral codes rather than drawing on disorganized bits of culture. Anglos have access to predominantly universalistic patterns while Asian Americans have access to both particularistic and universalistic criteria as equally legitimate platforms for moral reasoning. Similar culture-specific evocations of complex moral attitudes via routine embodiments have been observed for such cultural complexes as ideas of honor and masculinity, and notions of moral purity and impurity (Cohen and Leung 2009: 11281-1282, 283-1285) The evocation of complex cultural codes and moral sentiments via embodiment manipulations stands in unequivocal contradiction to the claim culture does not influence action via the generation of psychological (dispositional) proclivities (Swidler 1986: 283).

From this perspective, one of Bourdieu's most misunderstood books Masculine 
Domination (2001), can be interpreted as proposing the hypothesis that the primary way in which patriarchal gender "ideology" is encoded is via the hard embodiment mechanism (Uhlmann 2000; Uhlmann and Uhlmann 2005). For instance Bourdieu notes how a particular form of female subordination is encoded in the angle and direction of the eye gaze that women in Middle East and North Africa (MENA) region societies are expected (and come to habitually) hold (low and towards the ground; never meeting the gaze of other men directly and seldom looking up). Once hard-embodied, gendered culture can affect self-identity because it operates via routine pathways (well-honed habitual comportments) that self-reflection. Thus, persons come to perceive themselves acting in certain patterned ways (e.g. with self-assurance or subordinate tentativeness) rather than acting in particular ways because they are being guided by higher level reflective principles (which may be dissociated from the routine comportments and the cultural associations they activate (Lizardo 2017)).

\section{Bourdieu and The Soft Embodiment of Culture}

Ideologies may not only be "hard embodied"; they can also be subject to "soft embodiment" (Leung and Cohen 2007). The key difference between hard and soft embodiment is that in the latter, culture comes to be embodied not via the "online" direct manipulation of bodily posture or the handling of material artifacts but via the "offline" embodied simulation (Niedenthal et al. 2005) of the typical experiences we have as embodied persons (e.g. like looking at the world from a point of view). Soft embodiment phenomena lie behind the various embodiment effects shown in the processing of conceptual metaphors and sequencing effects in grammatical and idiomatic constructions (Glenberg and Robertson 2000; Ignatow 2007).

Gender ideologies, as Bourdieu (2001) intimated in Masculine Domination, may also be subject to soft embodiment. For instance, Uhlmann and Uhlmann (2005:95) 
review linguistic evidence regarding word ordering in conventional linguistic constructions involving two adjectives or prepositions (e.g. "up and down," "front and back," "good and bad," "here and there," etc.). The basic finding is that the first element in the pair is almost always the term associated either with the physical or psychological "egocentric" point of view of the speaker (a typical soft-embodiment effect among Westerners (Leung and Cohen 2007)). In locational terms that means that prepositional phrases depicting a point in space (or time) "close" to the subject will tend come first ("today and tomorrow" rather that "tomorrow and today"), and for valued adjectives the positive valued (which has been associated with the "self" among Westerners) will come first ("good and bad" rather than "bad and good.").

To show how gender ideology goes below discourse, Uhlmann and Uhlmann (2005) hypothesize that the precedence accorded to men in the larger culture should be homologous to that accorded to the self in linguistic constructions. They go to to review corpus data showing the overwhelming prevalence of the same effect for gendered pairs; thus "boys and girls," "men and women," and "husband and wife," are more conventionally sanctioned than the reverse. This suggests (except for domestic or familial contexts) that the primacy of men over women (e.g. the conceptual construction of men as primary, prototypical persons and women as deviations) is coded not only as explicit complex ideologies, but simple patterns of conventionalization in linguistic constructions

While Bourdieu's work can be faulted for the relative privileging of classification and categorization over morality (Ignatow 2009b), the work of Cerulo (1998) provides convergent evidence of the soft embodiment of moral prominence in linguistic sequences. Even though not initially couched in these terms, her findings are thoroughly compatible with, and in fact can be considered a prime example of the soft embodiment of culture phenomenon. As Cerulo shows, the typical sequencing of an active voice sentence involves the initial mention of an actor doing something to 
an object. This (typical) sequencing assigns prominence to the actor in relation to the object. This means that when third parties have to report on an event in which a morally privileged actor is the object of the action of a morally devalued actor, they must linguistic override this typical arrangement: The passive construction (which reverses order by making the object of the sentence first in the sequence). Cerulo (1998: 40-41) provides various examples of this soft embodiment phenomenon. These occur whenever violence is inflicted by a morally dubious actor on a set of morally worthy victims. Cerulo insightfully proposed that the reason these sentences are organized in this way has all to do with the assignment of cognitive priority to the patient: "victim sequences prioritize the characteristics of those whom violence strikes" (Cerulo 1998:40). Cerulo also noted that these types of sequences are "prototypical" for the case of "deviant" violence narratives.

In what Cerulo refers to as "performer sequences" violent acts which the conceptualizer presumes are morally justified---"normal violence" (Cerulo 1998:43)---in the eyes of his or her audience are presented using the (prototypical for events) active voice. Under these circumstances, we should expect reporters to not deviate from the prototypical active construction. Consistent with this hypothesis, Cerulo shows that performer sequences are almost invariably active voice constructions. The soft embodiment account naturally explains why this should be the case: in the active voice construction cognitive prominence falls naturally on the agent (not the patient) of the interaction symbolized by the verb in the finite clause. Because actors who do "bad things to bad people" (with the depiction of violent acts) are unproblematically conceptualized as being "good" they can be raised to cognitive prominence without resulting in any tension between the exogenous moral position of the actor and their prominent position in the linguistic construction. In this respect, moral prominence in discourse is subject to "soft-embodiment" in the same way as it is subject to "hard embodiment" in the elicitation and enactment of 
purification rituals that involve literal washing of the body (Cohen and Leung 2009:1283-1284).

\section{Implications of Bourdieu's (Embodied) Cognitive Sociology}

The existence of hard and soft embodiment of cultural phenomena have important implications for research and theory in cultural analysis in the social sciences. First, it is not enough to say one is taking an "embodied" or "embodiment" approach. It is important to specify what type of embodied approach one is attempting to deploy. As we have seen, some versions of embodiment imply weaker commitments when taken in isolation (e.g. embodied meaning, externalization); these are compatible with the existence of "soft" embodiment phenomena. Other approaches (e.g. cognitive unconscious, possibly coupled to phenomenological and embodied-meaning approaches) imply stronger empirical and theoretical commitments. Some long-standing cultural theories in sociology (e.g. structuralism and classical social phenomenology) cannot predict or even accommodate the existence of hard embodiment phenomena, especially the elicitation of complex cognitive, emotional, and even ideological mindsets from the simple manipulation of the body (Bourdieu 1990). In this respect, the biggest challenge (and promise) of Bourdieu's (embodied) cognitive sociology can be found here.

A key difference concerns the relative usefulness of the traditional battery of analytic methods in social science in the face of these issues. For soft-embodiment phenomena, traditional social scientific methods, ranging from the in-depth interview, to discourse, and text analysis can be calibrated to capture the traces of embodied cognition in meaning construction, especially those left behind in the spoken or written word (Ignatow 2009a, 2016). It is when researchers attempt to capture traces of hard-embodied culture that things get more problematic.

Culture that is hard-embodied requires the researcher to be attuned to the 
analog meaning of gestures, comportments, and ways of acting, observational strategies that keep the research "close to the action" (such as ethnography) are ideal (Wacquant 2004b). However, ethnography without the aid of proper cognitive theory will not be sufficient; researchers need to go to the field already sensitized to nature of the socio-cultural processes they will look for (Timmermans and Tavory 2012), otherwise their attention will be predictably drawn to the standard linguistically mediated symbols (Wacquant 2011). I close by providing some generative examples of how analysts (properly sensitized) can uncover hard-embodied culture in the field. Study Novices

One approach is to examine the conceptions of relative novices to the culture. Because culture patterns, to become hard-embodied, require repetition and practice, this practice is seldom accompanied by overt interpretations or detailed exegesis, we should find that relative novices in the process of internalizing correspondences between specific bodily comportments and higher-order belief and values, should be particularly transparent about this linkage.

The anthropologist Christina Toren (1999) suspected that conceptions of rank and hierarchy and their connection to higher-order belief systems that justify them are built up from routine comportments around ritual occasions, in particular everyday meals and the drinking of kava (beer made from the root vegetable) during special ceremonies. To verify this hypothesis, Toren asked a convenience sample of Fijian children ranging from five to eleven years old to examine a prepared drawing and provide the identity of unlabeled figures sitting around a table during the kava drinking ritual and during meals in the household (in effect eliciting "iconic" representations). She also asked them to provide their own drawings identifying where different persons (mother, father, chief, etc.) would be seated in similar circumstances.

Toren finds that by the age of six, Fijian children can reproduce the structural 
correspondence between gender and rank hierarchy and the above/below spatial axis of seating arrangements (it is a behavioral rule that men sit towards the "top" or head of the table- that is, the side of the table that points towards away from the main entrance to the house- and women and younger children sit toward the "bottom"), with younger children producing less ranking gradations than do older children (Toren 1999: 88-90). Toren concludes from these data that "an understanding of above/below in terms of its polar extremes occurs just before school age" (Toren 1999: 94). For these children the position of mother below "is the anchor for situations within the household...for prepared drawings of meals, all children chose the figure below to be mother...The figure said to be above was either father, father's elder brother, father's father, mother's brother or a 'guest'."

Getting Creative with Methods

Another approach is to expand the range of methodological tools, including the incorporation of video recording for capturing the hard-embodied bodily techniques that could easily be lost to the naked eye of the ethnographer. For instance, anthropologist N. J. Enfield (2005) shows that personal knowledge regarding the central analytic object of structuralist anthropology, namely kinship, is hard-embodied in "analog" motor schemes. Drawing on data from videotaped interviews of residents of Laos, Enfield shows that when prompted by the interviewer to explicitly verbalize the culturally accepted relations between different kinship roles, people use spatial bodily orientation along the right-left and up-down axis and gestures designed to show positions at locations "drawn" in the space immediately in the front of the informant's body to show the relative position of occupants of different positions in their kinship system. Thus, rather than being stored as amodal, abstract, categories, the "rules" of kinship exist as directly embodied sets of perceptual and motor skills, expressed as "bodily gymnastics" (Bourdieu 1990). 
Taking Embodiment Into the Field

Finally, Wacquant (2004a) provides an example of the fruitfulness of combining a phenomenological approach to embodiment in the field with a theoretical sensitivity for the body as the substrate of the cognitive unconscious (approaches (c) and (e) above). Here we get a rich description of the dynamics via which culture (in this case that of the boxing gym) becomes hard-embodied. This was particularly evident in the pedagogical style of the trainer who refused to believe boxing could be learned from books or by imitating static "pictures." The problem is that "[y]ou don't get a sense of movement. Boxin's movement...In a book everything's standin' still." (Wacquant 2004a: 101). The capacity to understand and "grasp" the meaning and telos of action by other agents at an implicit, bodily level, without recourse to an explicit "theory of mind" of other agents, coupled with the capacity to "mirror" the action of others and engage in implicit imitation of the bodily techniques of others, provide a different perspective of what it means to be "socialized" into the "culture" of a collectivity (see also Downey 2014). Some of these mechanisms were presaged in Bourdieu's (1990) own theoretical reflections regarding the "implicit pedagogy" that was necessary for full enculturation into a social group.

\section{References}

Barsalou, Lawrence W. 1999. "Perceptual Symbol Systems." Behavioral and Brain Sciences 22(4):577-609.

Barsalou, Lawrence W., Paula M. Niedenthal, Aron K. Barbey, and Jennifer A. Ruppert. 2003. "Social Embodiment." Psychology of Learning and Motivation 43:43-92.

Bloch, Maurice. 1986. "From Cognition to Ideology." Pp. 21-48. in Knowledge and Power: Anthropological and Sociological Approaches, edited by R. Fardon. Edinburgh: Scottish University Press.

Bourdieu, Pierre. 1970. “La Maison Kabyle Ou Le Monde Renversé.” Echanges et Communications, 
Mélanges Offerts à Claude Levi-Strauss à L'ocassion de Son 60éme Anniversaire 739-58.

Bourdieu, Pierre. 1984. Distinction: A Social Critique of the Judgement of Taste. Harvard University Press.

Bourdieu, Pierre. 1990. The Logic of Practice. Stanford University Press.

Bourdieu, Pierre. 1991. Language and Symbolic Power. Harvard University Press.

Bourdieu, Pierre. 1996a. The Rules of Art: Genesis and Structure of the Literary Field. Stanford University Press.

Bourdieu, Pierre. 1996b. The State Nobility: Elite Schools in the Field of Power. Stanford, CA: Stanford University Press.

Bourdieu, Pierre. 2001. Masculine Domination. Stanford University Press.

Cerulo, Karen A. 1998. Deciphering Violence: The Cognitive Structure of Right and Wrong. Psychology Press.

Cerulo, Karen A. 2015. “The Embodied Mind: Building on Wacquant's Carnal Sociology." Qualitative Sociology 38(1):33-38.

Chemero, Anthony. 2011. Radical Embodied Cognitive Science. MIT Press.

Clark, Andy. 1997. Being There: Putting Brain, Body, and World Together Again. Cambridge, MA: MIT Press.

Cohen, Dov and Angela K. Y. Leung. 2009. “The Hard Embodiment of Culture.” European Journal of Social Psychology 39(7):1278-89.

Collins, Harry. 2010. Tacit and Explicit Knowledge. Chicago: University of Chicago Press.

Crossley, Nick. 2001. "The Phenomenological Habitus and Its Construction.” Theory and Society 30(1):81-120.

Desmond, Matthew. 2007. On the Fireline. University of Chicago Press.

Downey, G. 2014. “'Habitus in Extremis': From Embodied Culture to Bio-Cultural Development.” Body \& Society. Retrieved (http://bod.sagepub.com/content/20/2/113.short).

Dreyfus, H. L. 1991. Being-in-the-World: A Commentary on Heidegger's Being and Time, División I. MIT Press.

Dreyfus, H. L. 1992. What Computers Still Can't Do: A Critique of Artificial Reason. Cambridge, MA: MIT Press.

Fiske, Alan P. 2004. "Four Modes of Constituting Relationships: Consubstantial Assimilation; Space, Magnitude, Time, and Force; Concrete Procedures; Abstract Symbolism.” Relational Models Theory: A Contemporary Overview 61-146.

Gallagher, Shaun. 2005. How the Body Shapes the Mind. Oxford: Oxford University Press. 
Glenberg, Arthur M. and Vittorio Gallese. 2012. "Action-Based Language: A Theory of Language Acquisition, Comprehension, and Production." Cortex; a Journal Devoted to the Study of the Nervous System and Behavior 48(7):905-22.

Glenberg, Arthur M. and David A. Robertson. 2000. "Symbol Grounding and Meaning: A Comparison of High-Dimensional and Embodied Theories of Meaning." Journal of Memory and Language 43(3):379-401.

Grosz, Elizabeth. 1987. “Notes towards a Corporeal Feminism.” Australian Feminist Studies 2(5):1-16.

Higgins, E. T. and C. M. Brendl. 1995. "Accessibility and Applicability: Some' Activation Rules' Influencing Judgment.” Journal of Experimental Social Psychology. Retrieved (http://www.sciencedirect.com/science/article/pii/S0022103185710116).

Hitlin, Steven and Jane Allyn Piliavin. 2004. "Values: Reviving a Dormant Concept." Annual Review of Sociology 30(1):359-93.

Hutchins, Edwin. 1995. Cognition in the Wild. Cambridge, MA: MIT Press.

Hutto, Daniel D. and Erik Myin. 2013. Radicalizing Enactivism: Basic Minds Without Content. MIT Press.

Ignatow, Gabe. 2016. "Theoretical Foundations for Digital Text Analysis." Journal for the Theory of Social Behaviour 46(1):104-20.

Ignatow, Gabriel. 2007. "Theories of Embodied Knowledge: New Directions for Cultural and Cognitive Sociology?” Journal for the Theory of Social Behaviour 37(2):115-35.

Ignatow, Gabriel. 2009a. "Culture and Embodied Cognition: Moral Discourses in Internet Support Groups for Overeaters." Social Forces; a Scientific Medium of Social Study and Interpretation 88(2):643-69.

Ignatow, Gabriel. 2009b. "Why the Sociology of Morality Needs Bourdieu’s Habitus." Sociological Inquiry 79(1):98-114.

Lakoff, George and Mark Johnson. 1999. Philosophy in the Flesh: The Embodied Mind and Its Challenge to Western Thought. New York: Basic Books.

Leung, Angela K., Lin Qiu, Laysee Ong, and Kim-Pong Tam. 2011. "Embodied Cultural Cognition: Situating the Study of Embodied Cognition in Socio-Cultural Contexts." Social and Personality Psychology Compass 5(9):591-608.

Leung, Angela K. Y. and Dov Cohen. 2007. "The Soft Embodiment of Culture: Camera Angles and Motion through Time and Space.” Psychological Science 18(9):824-30.

Lizardo, O. 2009. "Is a 'special Psychology' of Practice Possible? From Values and Attitudes to Embodied Dispositions.” Theory \& Psychology. Retrieved (http://tap.sagepub.com/content/19/6/713.short).

Lizardo, Omar. 2004. “The Cognitive Origins of Bourdieu's Habitus.” Journal for the Theory of Social 
Behaviour 34(4):375-401.

Lizardo, Omar. 2011. "Pierre Bourdieu as a Post-Cultural Theorist.” Cultural Sociology 5(1):25-44.

Lizardo, Omar. 2012. “The Three Phases of Bourdieu's U.S. Reception: Comment on Lamont.” Sociological Forum 27(1):238-44.

Lizardo, Omar. 2015. “Culture, Cognition and Embodiment.” Pp. 576-81 in International Encyclopedia of the Social \& Behavioral Sciences. Elsevier.

Lizardo, Omar. 2017. "Improving Cultural Analysis: Considering Personal Culture in Its Declarative and Nondeclarative Modes." American Sociological Review 0003122416675175.

Lizardo, Omar and Michael Strand. 2010. "Skills, Toolkits, Contexts and Institutions: Clarifying the Relationship between Different Approaches to Cognition in Cultural Sociology." Poetics 38(2):205-28.

Mauss, Marcel. 1973. “Techniques of the Body*.” Economy and Society 2(1):70-88.

McDonnell, T. E. 2016. Best Laid Plans: Cultural Entropy and the Unraveling of AIDS Media Campaigns. University of Chicago Press.

Mears, Ashley. 2011. Pricing Beauty: The Making of a Fashion Model. University of California Press.

Newell, Allen. 1980. "Physical Symbol Systems." Cognitive Science 4(2):135-83.

Niedenthal, Paula M., Lawrence W. Barsalou, Piotr Winkielman, Silvia Krauth-Gruber, and François Ric. 2005. "Embodiment in Attitudes, Social Perception, and Emotion." Personality and Social Psychology Review: An Official Journal of the Society for Personality and Social Psychology, Inc 9(3):184-211.

Pagis, Michal. 2010. "From Abstract Concepts to Experiential Knowledge: Embodying Enlightenment in a Meditation Center." Qualitative Sociology 33(4):469-89.

Pálsson, Gísli. 1994. “Enskilment at Sea.” Man 29(4):901-27.

Rohrer, Tim. 2010. "Embodiment and Experientialism." in The Oxford Handbook of Cognitive Linguistics, edited by Dirk Geeraerts And. Oxford University Press.

Schubert, Thomas W. 2005. "Your Highness: Vertical Positions as Perceptual Symbols of Power." Journal of Personality and Social Psychology 89(1):1-21.

Schubert, Thomas W. and Gün R. Semin. 2009. "Embodiment as a Unifying Perspective for Psychology." European Journal of Social Psychology 39(7):1135-41.

Schwartz, Barry. 1981. Vertical Classification: A Study in Structuralism and the Sociology of Knowledge. University of Chicago Press.

Strand, Michael and Omar Lizardo. 2015. "Beyond World Images: Belief as Embodied Action in the World." Sociological Theory 33(1):44-70. 
Strauss, Claudia and Naomi Quinn. 1997. A Cognitive Theory of Cultural Meaning. Cambridge University Press.

Timmermans, Stefan and Iddo Tavory. 2012. "Theory Construction in Qualitative Research: From Grounded Theory to Abductive Analysis.” Sociological Theory 30(3):167-86.

Toren, Christina. 1999. Mind, Materiality, and History: Explorations in Fijian Ethnography. Psychology Press.

Uhlmann, Allon. 2000. "Incorporating Masculine Domination: Theoretical and Ethnographic Elaborations." Social Analysis: The International Journal of Social and Cultural Practice 44(1):142-61.

Uhlmann, Allon J. and Jennifer R. Uhlmann. 2005. "Embodiment below Discourse: The Internalized Domination of the Masculine Perspective.” Women's Studies International Forum 28(1):93-103.

Wacquant, Loïc. 2013. "Homines in Extremis: What Fighting Scholars Teach Us about Habitus." Body \& Society 20(2):3-17.

Wacquant, Loïc J. D. 2004a. Body \& Soul: Notebooks of an Apprentice Boxer. Oxford University Press.

Wacquant, Loïc J. D. 2004b. "Following Pierre Bourdieu into the Field.” Ethnography 5(4):387-414.

Waskul, Dennis D. and Phillip Vannini. 2006. "Introduction: The Body in Symbolic Interaction." Body/embodiment: Symbolic Interaction and the Sociology of the Body 1-18.

Wheeler, Michael. 2005. Reconstructing the Cognitive World: The Next Step. MIT Press.

Wilson, Margaret. 2002. "Six Views of Embodied Cognition." Psychonomic Bulletin \& Review 9(4):625-36.

Wilson, Robert A. 2004. Boundaries of the Mind: The Individual in the Fragile Sciences - Cognition. Cambridge University Press.

Winchester, Daniel. 2008. "Embodying the Faith: Religious Practice and the Making of a Muslim Moral Habitus." Social Forces; a Scientific Medium of Social Study and Interpretation 86(4):1753-80. 